\title{
Binocular interaction of orientation and spatial frequency channels: Evoked potentials and observer sensitivity
}

\author{
VERNON L. TOWLE, M. RUSSELL HARTER, and FRED H. PREVIC \\ University of North Carolina, Greensboro, North Carolinia 27412
}

\begin{abstract}
The interaction between size and orientation feature processing in the human visual system was investigated. Both observer sensitivity $\left(d^{\prime}\right)$ and the visual evoked potential (VEP) to test gratings flashed to one eye were investigated as a function of the nature of a continuously presented suppressing grating viewed either by that same eye or the opposite eye. The test and suppressing gratings were varied both in bar width $\left(9^{\prime}\right.$ vs. $\left.36^{\prime}\right)$ and orientation (vertical vs. horizontal). The continuous grating intra- and interocularly suppressed the monocular VEPs to the flashed grating, the specificity of the suppression depending on the latency at which VEP amplitude was measured. VEP amplitude measured at early latencies (100-125 msec) was suppressed primarily when the flashed and continuous gratings were the same orientation, regardless of size. Starting at about $200 \mathrm{msec}$, and thereafter, VEP amplitudes were suppressed when the continuous bars were either the same orientation or size as the flashed bars. Late latencies, starting at $220 \mathrm{msec}$, and thereafter, were suppressed primarily when the bars in the two gratings were the same orientation and size. The reduction in observer sensitivity $\left(d^{\prime}\right)$ paralleled the changes found in the late VEP measures. These effects were evident under both the intraocular and interocular suppressing conditions. This pattern of VEP suppression, measured across eight points in the VEP waveform, was interpreted as indicating the existence of a sequence of channels that are specific first to a particular grating orientation, then to either a particular grating spatial frequency or orientation, and finally to the conjunction of a particular orientation and spatial frequency. Both sequential and parallel feature processing appears to take place in the human visual cortex, with grating orientation being encoded earlier than grating size.
\end{abstract}

The existence of orientation and spatial frequency channels in the human visual system has been demonstrated with adaptation paradigms using both psychophysical (Blakemore \& Campbell, 1969, Blakemore, Nachmias, \& Sutton, 1970; Gilinski \& Mayo, 1971; Pantle \& Sekuler, 1968; Wyatt, 1974) and visual evoked potential (VEP) techniques (Blakemore \& Campbell, 1969; Mecacci \& Spinelli, 1976; Smith \& Jeffreys, 1978). Feature channels also have been observed in experiments using other paradigms with both psychophysical (Abadi, 1976; Campbell \& Kulikowski, 1966; Campbell \& Robson, 1968) and evoked potential measures (Campbell \& Maffei, 1970; Harter, Previc, \& Towle, 1979; Harter, Towle, \&

This experiment was the PhD dissertation project of the first author while at the University of North Carolina at Greensboro. It was supported in part by a Sloan Foundation grant. Reprints may be obtained from the second author. Portions of these data were presented at the Association for Research in Vision and Ophthalmology, Sarasota, Florida, 1978, and were published in the proceedings of the NATO Conference on Human Evoked Potentials, Konstanz, West Germany, 1978 (see Harter, Previc, \& Towle, 1979). V. L. Towle's present address: Department of Ophthalmology, Tufts-New England Medical Center, 171 Harrison Ave., Boston, Massachusetts 02111.
Musso, 1976; Musso \& Harter, 1975). The interocular transfer of these effects indicates that they are most likely mediated by binocular cortical channels (Blakemore \& Campbell, 1969; Campbell \& Maffei, 1971; Gilinsky \& Doherty, 1969; Harter et al., 1976; Harter, Towle, Zakrzewski, \& Moyer, 1977; Maffei \& Fiorentini, 1972; Ware \& Mitchell, 1974).

The above studies, having manipulated only one stimulus feature at a time, have not distinguished between "feature specificity" (e.g., specificity to a particular orientation, regardless of spatial frequency) and "grating specificity" (i.e., specificity to the conjunction of both a particular orientation and spatial frequency. ${ }^{1}$ It is possible that the suppression observed in these experiments is due to the suppression of "grating-specific channels," rather than channels specific to individual stimulus features. This possibility has been tested in a few psychophysical experiments which have manipulated more than one stimulus feature. These studies have indicated that the perceived spatial frequency shift is orientation specific (Blakemore \& Sutton, 1969; Blakemore et al., 1970) but that the tilt aftereffect is not size specific (Campbell \& Maffei, 1971; Parker, 1972). Other 
studies have reported spatial frequency specificity for orientation illusions (Georgeson, 1973; Ware \& Mitchell, 1974). In order to clarify the differences between orientation-, spatial frequency-, and gratingspecific channels, the present study investigated the results of manipulating both the size and orientation of bars in gratings using a VEP suppression paradigm.

One advantage of using VEPs over psychophysical measures is that VEPs reflect the temporal sequence of neural events antecedent to the psychophysical response. The specificity and latency of the VEP suppression has implications for how size and orientation channels might be organized in relation to each other. If, for example, an early component of the VEP is influenced by stimulus orientation while a later component is influenced by stimulus spatial frequency, it may be concluded that the nervous system processes the orientation feature earlier than the size feature. Analysis of the time-course of VEP suppression has allowed us to investigate the progression from orientation-, to spatial frequency-, to grating-specific suppression in the human visual system.

\section{METHOD}

\section{Subjects}

Five males and one female (ages 14-50 years) volunteered to serve as subjects in this experiment. All six subjects had visual acuities correctable to $20 / 20$ or better, steroacuities better than $20 \mathrm{sec}$ of arc as measured with a Bausch-Lomb Ortho-rater, and no detected astigmatism (except M.R.H., who had a slight amount in the vertical plane). Three of the six subjects had served in previous experiments in this laboratory; two of them (M.R.H. and V.L.T.) were aware of the purpose of the experiment.

\section{Visual Stimulation}

The visual patterns used in this experiment were black and white square-wave gratings photographically reproduced on transparency film (contrast $=.9$ ). Two bar sizes (spatial frequencies) were presented at vertical and horizontal orientations, one with 9-min bars ( $3.3 \mathrm{cycles} / \mathrm{deg}$ ) and another with $36-\mathrm{min}$ bars $(.83 \mathrm{cycles} / \mathrm{deg})$. These sizes were chosen because their fundamental spatial frequencies are separated by two octaves and, although their harmonics overlap to some degree, they primarily activate different size channels (Blakemore \& Campbell, 1969; Harter et al., 1976). Likewise, the 90 -deg difference in orientation is sufficient to activate different orientation channels (Campbell \& Maffei, 1970).

Independent stimulation of each eye was obtained by means of a haploscope (see Figure 1). The left and right eyes each viewed continuously illuminated $8 \times 10 \mathrm{deg}$ fields, which were optically superimposed. Depending on the viewing condition, one of these continuously illuminated fields contained gratings of 9-min vertical, 36-min vertical, 9-min horizontal, or 36-min horizontal bars, while the other contained a diffuse field of equal spaceaverage luminance $(4 \pm 1 \mathrm{~mL}){ }^{2}$ Monocular evoked potentials were obtained by flashing a grating (7-deg-diam field) of either 9-min vertical or $36-\mathrm{min}$ horizontal bars to the right eye. The patterns were mounted in a random access stimulator (Musso \& Harter, 1975 ) and were back-illuminated with a $10-\mu \mathrm{sec}$ light flash generated by a Grass PS-2 photostimulator. The flashed gratings appeared once every $780 \mathrm{msec}$ and were $2.4 \mathrm{log}$ units above psychophysical threshold (as measured with neutral density filters). There were two viewing conditions: the intraocular viewing condition, where both the flashed gratings and the continuously

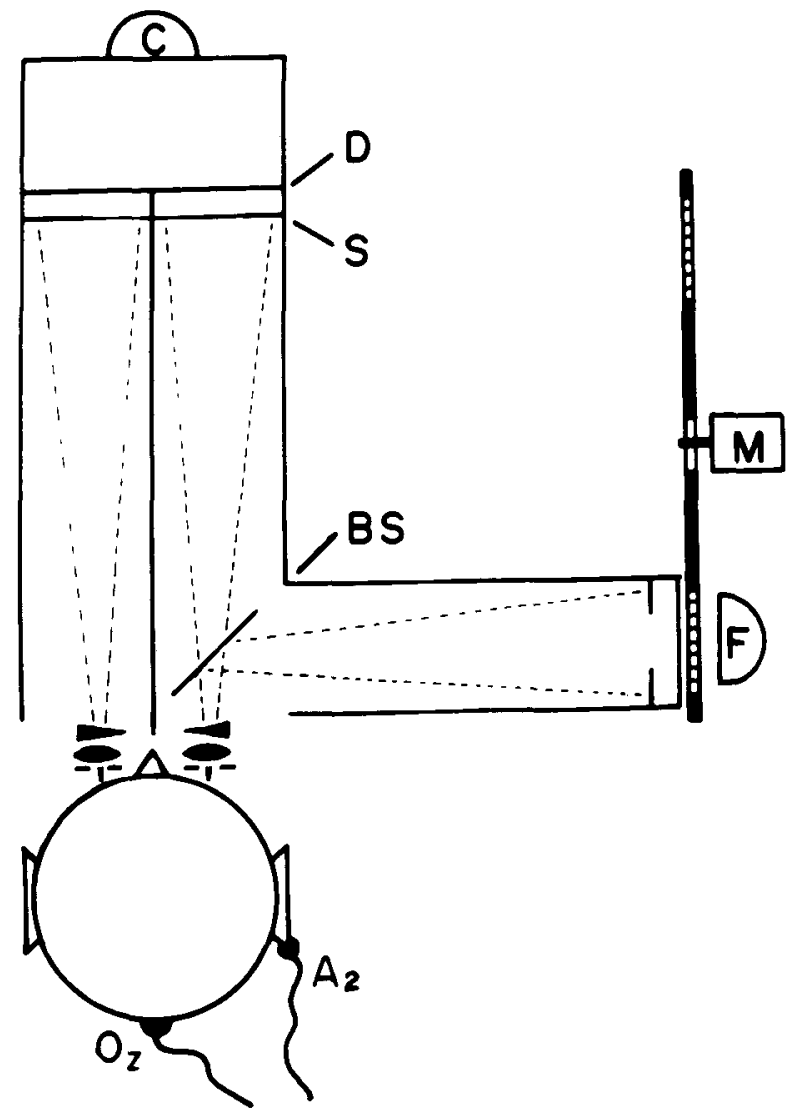

Figure 1. Experimental apparatus used to present stimuli. Subjects dichoptically viewed suppressing stimuli (S) (a grating for one eye and a diffuse field of equal luminance for the other), illuminated by a continuous incandescent light source $(C)$ behind a diffusing screen (D). A beam splitter (BS) caused flashed stimuli (F) from the random-access stimulator (M) to appear superimposed on continuous stimuli (S) viewed by the right eye. Subjects viewed the stimuli through $+1-D$ spherical lenses, 8- $\Delta$ prisms, and 1-mm artificial pupils from a distance of $53 \mathrm{~cm}$.

presented gratings were viewed by the same (right) eye while the left eye continuously viewed a diffuse field, and the interocular viewing condition, where the flashed and continuous gratings were viewed by the right and left eye, respectively, the right eye continuously viewing diffuse light. The ambient illumination of the subject cubicle was $1 \mathrm{~mL}$.

\section{Procedure}

In an initial 2-h session, the visual characteristics of the subject were ascertained and the subject became familiar with the laboratory procedures and practiced the psychophysical task. In addition, control data were collected in which the phase of the flashed and nonflashed gratings was varied within the intraocular viewing condition to insure that the relative phase of the gratings could not account for the results. The main part of the experiment consisted of the subjects' receiving the 16 experimental conditions (four continuous gratings - two bar orientations by two bar sizes-by two flashed gratings by two viewing conditions) in a completely counterbalanced Latin square design. The continuous gratings were changed after each block of 32 flashed gratings (which lasted about $45 \mathrm{sec}$ ). After all four continuous gratings 
FLASHED

$9 \mathrm{~V}$

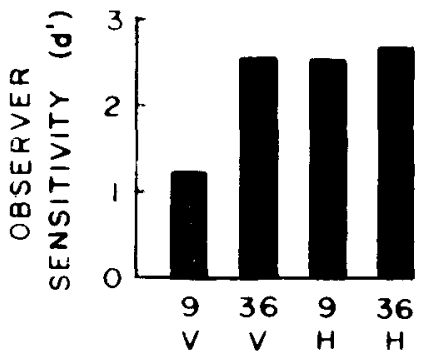

CONTINUOUS
GRATING

$36 \mathrm{H}$

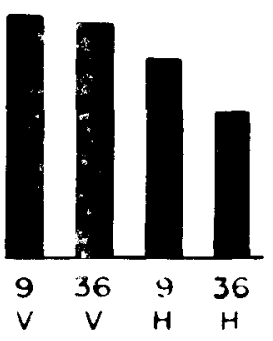

GRATING
Figure 2. Average observer sensitivity ( $\left.d^{\prime}\right)$ for detecting the flashed gratings as a function of the continuous gratings. Data have been averaged across intraocular and interocular viewing conditions, 4 replications, 64 flashes, and 6 subjects $(n=3,072)$. (V and $H$ refer to vertical and horizontal grating orientation; 9 and 36 refer to bar width of gratings in minutes of arc.)

had been viewed in this manner, they were viewed again in the reverse order. Responses to a total of 64 flashed gratings were obtained under each continuous grating condition. After a 5-min rest period, the procedure was repeated for the other flashed grating and viewing condition. Subjects initiated the train of flashes at the beginning of each condition and could stop them if they needed to blink or rest their eyes. Four replications of this procedure were obtained, each on a different day.

\section{Psychophysical Task}

Randomly interspersed among the 64 flashed gratings were 64 flashes of diffuse light equal in space-average luminance to the gratings. The subject's task was to perform a finger-lift reaction time (RT) response to the pattern flashes but not to the diffuse flashes. If the subject did not respond within $375 \mathrm{msec}$ after the flashed grating, feedback was given in the form of a "click" via a speaker in the ceiling of the subject cubicle. The detectability (d') of the flashed grating, as a function of the intraocular and interocular suppression effects of the continuous grating, was calculated from the subject's "hits" (RTs made within 375 msec after the flashed grating) and "false alarms" (RTs made within $375 \mathrm{msec}$ after the diffuse flash), using signal detection theory (Green \& Swets, 1966). Evoked potentials were not obtained to the diffuse flashes.

\section{Visual Evoked Potentials}

Recording procedures were similar to those of previous studies from this laboratory (Harter et al., 1976). EEGs were recorded monopolarly by means of a 9-mm Grass gold-cup scalp electrode placed $2.5 \mathrm{~cm}$ above the inion on the midline referenced to the right earlobe. They were amplified with a Grass Model 7WC polygraph with $1 / 2$ amplitude high- and low-frequency filters set at 35 and $1 \mathrm{~Hz}$, respectively. Evoked cortical potentials were averaged for 512 misec after the flashed gratings with a Fabritek 1062 signalaveraging computer. EEGs were monitored for movement and other artifacts on an oscillosope. The subject was situated in an electrically shielded, partially soundproofed cubicle, into which a sufficient level of white noise was piped to mask extraneous noises.

\section{Statistical A nalyses}

The analysis of variance program from the UCLA Biomedical statistical package was used to analyze the psychophysical and evoked potential data (Dixon, 1975). A fixed effect repeated measures model with subject interactions used as error terms was used for the ANOVAs. Newman-Keuls multiple range tests
(Winer, 1971) were used to assess the statistical significance of differences between treatment means when significant $F$ ratios were obtained. Additional ANOVAs were conducted to assess the statistical significance of the effects of changing the features common to the flashed and continuous gratings (spatial frequency, orientation, and the interaction between these two features).

\section{RESULTS}

\section{Psychophysical Data}

The go/no RT task (Harter \& Previc, 1978; Harter \& Salmon, 1972; Schwent, Hillyard, \& Galambos, 1976) was quantified by calculating the detectability (d') of the flashed gratings with 9-min vertical and 36-min horizontal bars under each of the intraocular and interocular viewing (suppressing) conditions. Hits and false alarms were summed across the four replications of each condition before the d's were calculated $(\mathrm{N}=512)$. The effects of the continuous gratings on the detectability of the flashed grating reflected a pattern-specific interaction $[F(3,15)=69.2$, $p<$ $.01]$. Newman-Keuls multiple range tests applied separately to the 9-min vertical and 36-min horizontal flashed bar conditions revealed that when the flashed and continuous bars were identical in size and orientation, the detectability of the flashed gratings was significantly lower than under the other conditions (see Figure 2). The differences between the intraocular and interocular viewing conditions did not approach statistical significance.

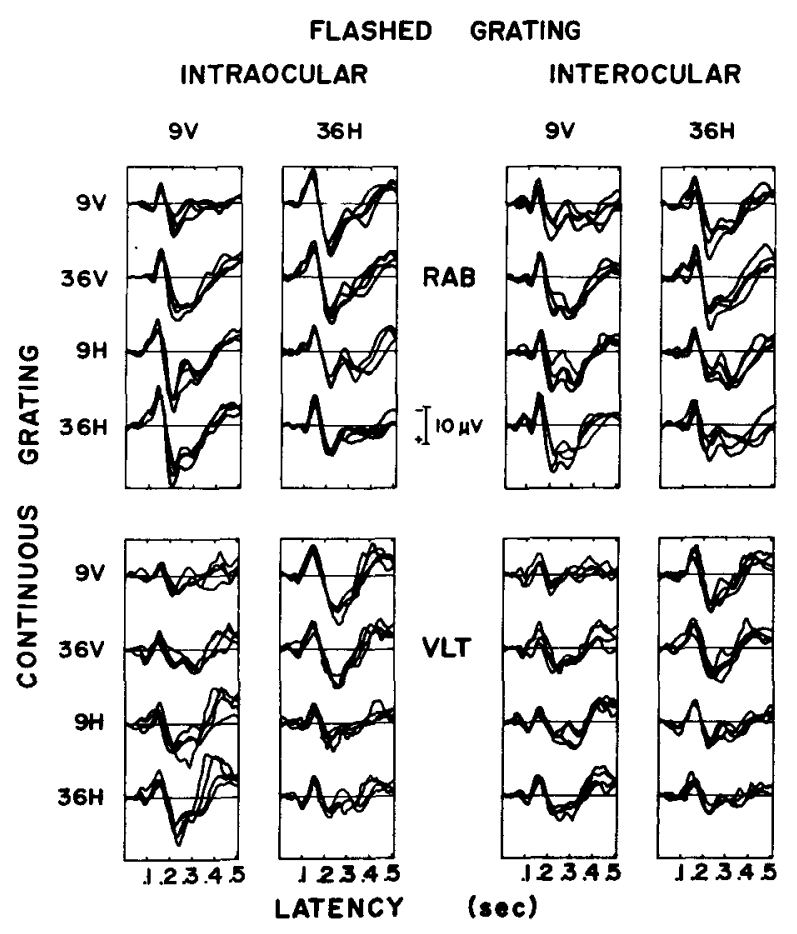

Figure 3. Average evoked potentials from two subjects (R.A.B. and V.L.T.) from flashed gratings as a function of continuous gratings and viewing conditions $(n=64)$. (See Figure 2 for explanation of abbreviations.) 


\section{Visual Evoked Potentials}

The X-Y plots of the data from each of the four replications of each experimental condition were traced onto graph paper in such a way that the average voltage of the first $50 \mathrm{msec}$ of each VEP equaled zero. All amplitude measurements were made relative to this zero baseline. The most consistent and recognizable deflection was a negative peak between 125 and $195 \mathrm{msec}(\overline{\mathrm{N} 150})$ that was evident in each VEP waveform of all subjects (see Figure 3). It was followed by a "w-shaped" complex with two positive peaks. These two positive peaks ranged in latency from 200 to $250 \mathrm{msec}$ and from 280 to $380 \mathrm{msec}$, and were termed $\overline{\mathbf{P} 230}$ and $\overline{\mathbf{P 3 2 0}}$, respectively. A final negative deflection, which peaked between 400 , and $500 \mathrm{msec}$, was evident in most subjects. The amplitude and latency of $\overline{\mathrm{P} 230}$ and $\overline{\mathrm{P} 320}$ was measured using a 50-msec window. The latency of the $50-\mathrm{msec}$ window for $\overline{\mathrm{P} 320}$ was allowed to vary across subjects, the exact latency being defined by the greatest amplitude positive peak (negative-to-positive and positive-to-negative deflection) in all of the VEPs for each subject.

Since the peaks of raw VEP waveforms may not be the the most appropriate VEP measure of information processing (Donchin \& Heffley, 1978; Harter \& Previc, 1978; Harter \& Salmon, 1972), additional amplitude measures were obtained at fixed latencies based on the changes in VEP waveform due to the effects of the continuous gratings. The specific latencies were determined by the maximum deflections of "difference potentials," generated by taking the four VEPs to a given flashed grating, obtained under the

Figure 4. (A) Quantified VEPs reflecting suppression of VEP amplitude to the flashed grating due to the features in the continuous grating which were common to the flashed grating. (B) Difference in VEP amplitude due to changing the continuous grating from having neither feature in common with the flashed grating to having size (delta $S$ ) or orientation (delta $O$ ) in common with the flashed grating. The changes reflect "pure" size and orientaton effects in that they were obtained when only that feature was common to both the flashed and continuous grating. (C) Difference in VEP amplitude due to changing the continuous grating from having one feature in common with the flashed grating, either bar size or orientation, to having both features in common with the flashed grating. Here, the effects of changing one feature of the continuous grating is confounded with any effects due to changing the continuous stimulus so that it is identical to the flashed grating. Thus, these changes may not reflect "pure" size or orientation effects. (D) Difference in VEP amplitude due to changing the continuous grating from having neither feature to having both features in common with the flashed grating (delta $S$ and $O$, dotted line). Predicted difference in VEP amplitude due to changing both features of the flashed and continuous grating - the algebraic summation of the individual effects of size and orientation taken from (B) (delta $\mathbf{S}+$ O, dotted line). For A, B, C, and D, data were averaged across six subjects, four replications, two methods of stimulation, and two types of flashes. four continuous grating conditions and subtracting them from one another (see Figure 4). Any deviations from a straight line in these difference potentials indicated the effect of changing the size, orientation, or size and orientation of the continuous gratings. On the basis of the latency of the "functional components" indicated by the difference potentials in the present and previous experiments (Harter \& Previc, 1978; Harter et al, 1976), VEP amplitude was measured from baseline at $75,100,125,275$, and $425 \mathrm{msec}$. Table 1 gives the average amplitude and latency of all 11 VEP measures, along with their standard deviations. These and all subsequent values were obtained from the raw waveforms. The difference potentials are only being used to illustrate changes in the raw waveforms. Although latency changes can be confounded with amplitude changes using a subtraction procedure, the latency changes

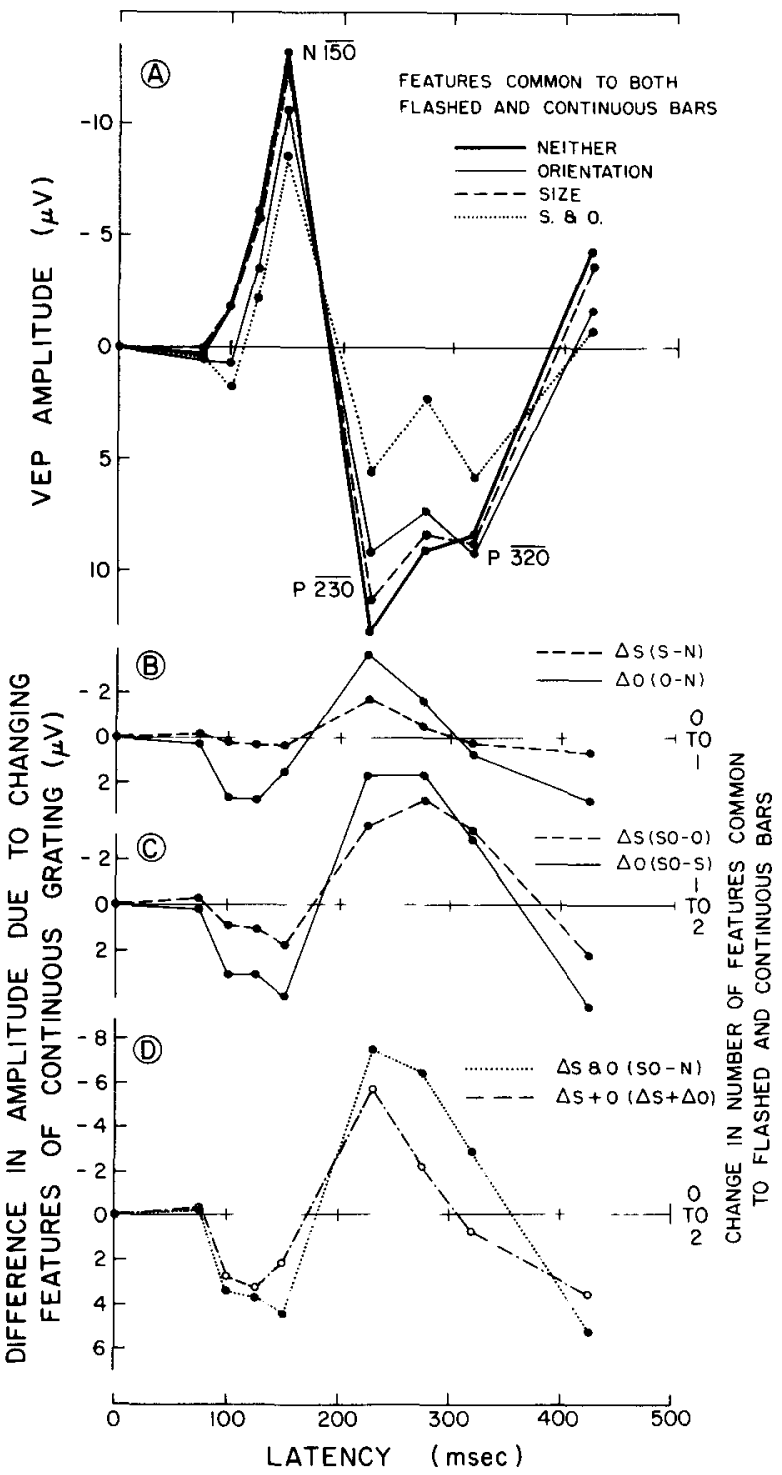


Table 1

Means and Standard Deviations of All 11 VEP Parameters

\begin{tabular}{|c|c|c|c|c|}
\hline \multirow{2}{*}{$\begin{array}{c}\text { VEP } \\
\text { Measure }\end{array}$} & \multicolumn{2}{|c|}{$\begin{array}{c}\text { Amplitude } \\
\text { (in Microvolts) }\end{array}$} & \multicolumn{2}{|c|}{$\begin{array}{c}\text { Latency } \\
\text { (in Milliseconds) }\end{array}$} \\
\hline & Mean & SD & Mean & SD \\
\hline $75 \mathrm{msec}$ & .21 & 1.54 & $75^{*}$ & $.0^{*}$ \\
\hline $100 \mathrm{msec}$ & -.20 & 2.20 & $100^{*}$ & $.0^{*}$ \\
\hline $125 \mathrm{msec}$ & -2.79 & 2.58 & $125^{*}$ & $.0^{*}$ \\
\hline N150 & -7.16 & 6.12 & 151 & 9.25 \\
\hline$\overline{\mathrm{P} 230}$ & 6.16 & 3.76 & 230 & 15.49 \\
\hline $275 \mathrm{msec}$ & 4.24 & 3.47 & $275^{*}$ & $.0^{*}$ \\
\hline P320 & 5.10 & 2.74 & 320 & 22.49 \\
\hline $425 \mathrm{msec}$ & -1.39 & 3.78 & $425^{*}$ & $.0^{*}$ \\
\hline
\end{tabular}

*By definition.

associated with the range of spatial frequencies used in this experiment are not large enough to present a problem. The latency of $\overline{\mathrm{N} 150}$ and $\overline{\mathrm{P} 230}$ did not change significantly between suppression conditions.

\section{Definition of Terms}

The following definitions will be used in this paper: An orientation or orientation-specific effect is that change in the VEP to the flashed grating which may be attributed to a change in the orientation of the continuous grating and is not dependent on the spatial frequency of the continuous grating (the orientation effects which may be obtained when the spatial frequency of the continuous grating is not the same as the flashed grating). A size or size-specific effect is that change in the VEP to the flashed grating which may be attributed to a change in the spatial frequency, or bar width, of the continuous gratings and is not dependent on the orientation of the continuous grating (the size effects which may be obtained when the orientation of the continuous grating is not the same as the flashed grating). A grating, or pattern-specific effect, is that change in the VEP to the flashed grating which may be attributed to the conjunction of the same spatial frequency and orientation in the flashed and continuous gratings and may not be attributed simply to the additivity of orientation and spatial frequency effects per se.

Visual inspection of the data (see Figure 3) and statistical analyses indicated that changes in VEP amplitude to the flashed gratings, due to changes in the continuous gratings, were due to the features in common to both the flashed and continuous gratings and not due to the features of the continuous grating alone. For example, $9 \mathrm{~V}$ and $36 \mathrm{H}$ continuous gratings had similar effects on the VEPs to $9 \mathrm{~V}$ and $36 \mathrm{H}$ flashed gratings, respectively. To simplify the presentation and statistical analyses of the data, therefore, the data were averaged across the two flashed grating conditions on the basis of the features common to both the flashed and continuous gratings (see Figure 4A). The effects of changing the orienta- tion (orientation effect) or width (size effect) of the bars in the continuous grating from different to the same as the flashed grating, and the interaction between the size and orientation effects, are shown in Figures 4B, 4C, and 4D. The statistical significance of these effects is shown in Figure 7.

The effects of changing one feature, the size or orientation of the bars of the continuous grating, on VEPs to the flashed gratings may be considered when the other feature is either not common or common to both the flashed and continuous gratings (see Figures 4B and C, respectively). These two types of effects were similar, with the following exceptions: first, the effect of changing the continuous grating from zero to one feature in common with the flashed grating (see Figure 4B) was smaller in magnitude than that due to a change from one to two features in common (Figure 4C); and second, the effects of changing the bar size of the continuous gratings influenced VEPs to the flashed grating between 100 and $150 \mathrm{msec}$ only when bar orientation was common to both gratings (see Figure $4 \mathrm{C}$ ). The latter manipulation would be expected to cause more suppression because both "feature-specific" and "gratingspecific" suppression are involved.

\section{Time-Course of Orientation- and Size-Specific Effects}

The 100-msec, 125-msec, and $\overline{N 150}$ amplitude measures all reacted in a similar manner to the stimulus manipulations. They were primarily sensitive to the relative orientation of the flashed and continuous bars and relatively insensitive to the relative size of the bars. When the flashed and continuous gratings were of the same orientation, the amplitude

\section{FLASHED GRATING}

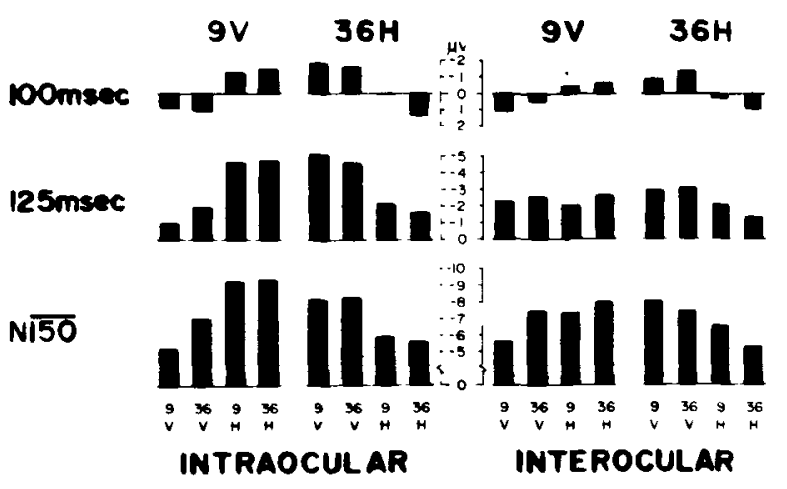

CONTINUOUS GRATING

Figure 5. Early VEP measures. Average amplitude $(\mu \mathrm{V})$ at 100 msec, $125 \mathrm{msec}$, and $\overline{\mathrm{N150}}$ as a function of flashed grating, continuous grating, and viewing condition. Data have been averaged across four replications, and six subjects $(n=1,536)$. (See Figure 2 for explanation of abbreviations.) 
of these measures was less negative (more positive) than when the flashed and continuous gratings were of different orientations (see Figure 5). This effect was truly orientation-specific, since it occurred regardless of the spatial frequency of the continuous grating. For example, VEPs to the $9 \mathrm{~V}$ grating shifted positive when the continuous grating was changed from $36 \mathrm{H}$ to $36 \mathrm{~V}$, a change from zero to one feature in common (see Figure 4B), as well as from $9 \mathrm{H}$ to $9 \mathrm{~V}$, a change from one to two features in common (see Figures $4 \mathrm{C}$ and 5). This orientation effect was statistically significant at 100 and $125 \mathrm{msec}$ and was more evident in the intraocular than in the interocular viewing conditions (see Figure 5). Size-specific effects were less evident between 75 and $150 \mathrm{msec}$ poststimulus. The effects of the relative size of the flashed and continuous gratings were not statistically significant on these VEP amplitude measures (see Figure 5), even when these gratings were the same orientation (dashed line, Figure $4 \mathrm{C}$ ).

In contrast to the earlier measures, VEP amplitudes measured at 230 and $275 \mathrm{msec}$ were influenced by both the relative orientation and spatial frequency of the gratings (see Figures 6 and 7). The orientationspecific effect was greatest at $\overline{\mathrm{P} 230}[\mathrm{~F}(1,5)=105.97$, $\mathrm{p}<.002]$. The size-specific effect was first statistically significant at $230 \mathrm{msec}[\mathrm{F}(1,5)=9.44, \mathrm{p}<$ .03] and increased to its maximum at $275 \mathrm{msec}$ $[\mathrm{F}(1,5)=34.82, \mathrm{p}<.002]$. Both the size- and orientation-specific effects declined following $275 \mathrm{msec}$ poststimulus.

It should be noted that a change from one to two features in common to the flashed and continuous gratings confounds two effects-one due to the change in one feature per se and the other due to the unique effect of a change that makes both features common to the flashed and continuous gratings. The latter effect is reflected in the present data in two ways. First, there were significant interactions between the effects of the orientation and size of bars in the continuous gratings, relative to the flashed gratings, at $275 \mathrm{msec}[\mathrm{F}(1,5)=31.09, \mathrm{p}<.003]$ and $320 \mathrm{msec}[\mathrm{F}(1,5)=11.94, \mathrm{p}<.02]$ (also see Figure 7). These interactions indicated that the effects of one feature in common were, in part, dependent on the presence of the other. Second, the suppression of VEP amplitude due to changing both features of the continuous stimulus from different from to the same as the flashed stimulus (see Figure 4D, dotted line) was greater than the summation of the individual effects of orientation and size alone (see Figure 4D, open circles). This unique effect, which is due to the conjunction of a particular orientation and size of bar, and which was greater than the summation of the effects of the individual features contained in the conjunction, was greatest from 275 to $320 \mathrm{msec}$ poststimulation. It may be noted that the behavioral measure of observer sensitivity $\left(d^{\prime}\right)$, determined from RT responses occurring at about this same

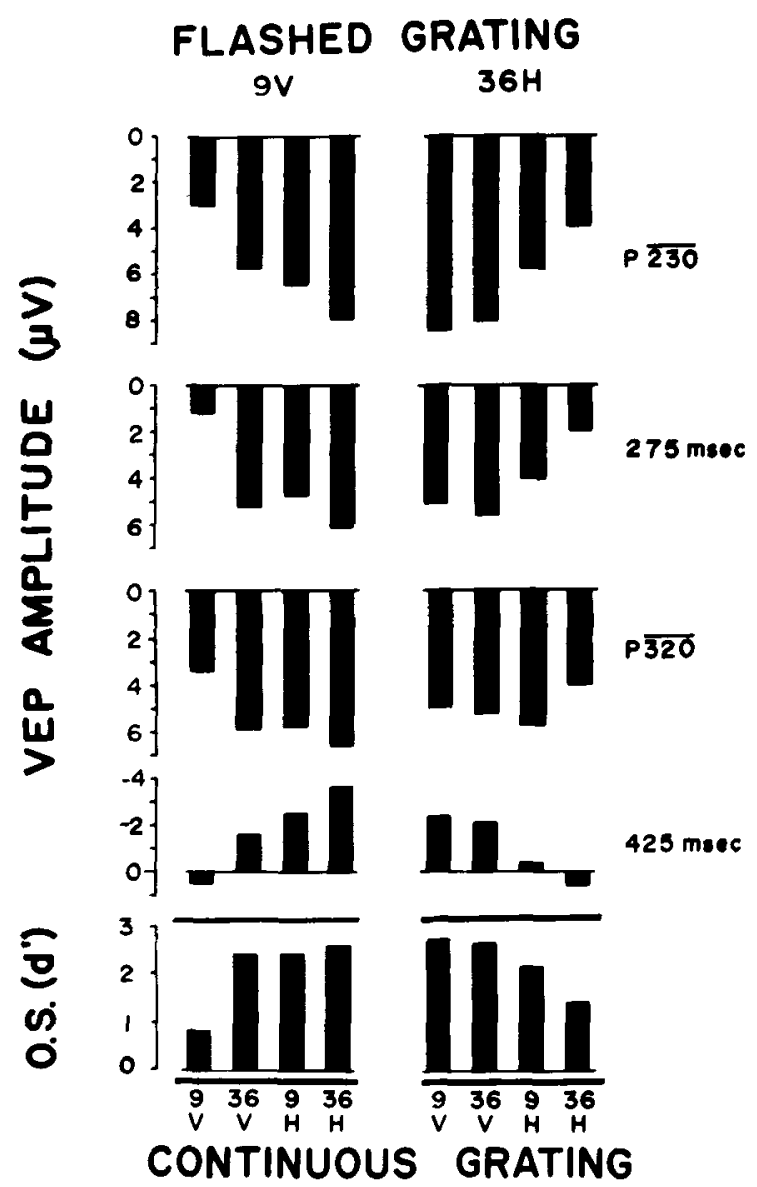

Figure 6. Late VEP measures and observer sensitivity. Top four graphs: Average amplitude $(\mu V)$ of evoked potential waveform at P230, 275 msec, P320, and $\mathbf{4 2 5}$ msec as a function of continuous gratings. Bottom graph: Average observer sensitivity (d') for detecting flashed gratings as a function of continuous gratings. Data have been averaged across two viewing conditions, four replications, and six subjects $(n=3,072)$. (See Figure 2 for explanation of abbreviations.)

period of time, also reflected the unique effects of the conjunction of that particular size and orientation contained in the flashed grating.

\section{Additional Findings}

Although RT latency was not directly measured in this experiment, it apparently decreased throughout the study, since the number of hits (RTs less than $375 \mathrm{msec}$ ) increased with each replication. Accordingly, N150 decreased in latency across the four replications $[F(3,15)=5.06, p<.025] . \overline{P 320}$ peaked significantly later when the continuous and flashed gratings were identical $[F(3,15)=15.02, p<.01]$, most likely reflecting increased processing time under the more difficult conditions.

\section{Summary}

Changes in the amplitude of the two major deflections of the VEP waveforms of this experiment, a negative deflection from about 75 to $175 \mathrm{msec}$ and a 


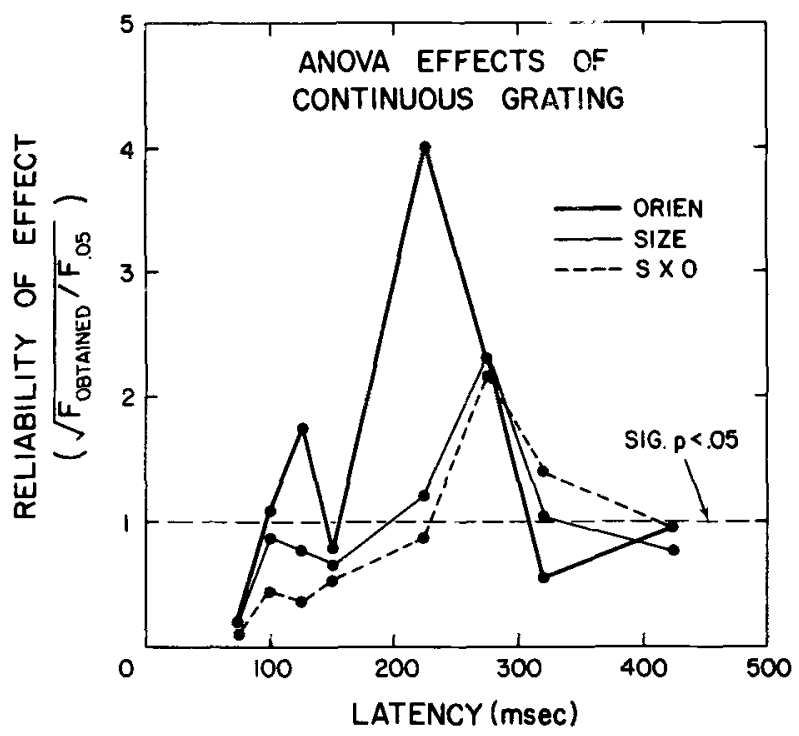

Figure 7. Results of the analysis of variance reflecting sources of variability due to changing the orientation $(O)$ or size (S) of the bars of the continuous grating from different to the same as the bars in the flashed grating and the interaction between these orientation and size effects ( $S$ by $O$ ). The horizontal axis indicates the latency at which the effects on VEP amplitudes were measured. The vertical axis scale indicates the magnitude of the obtained $F$ ratio $(1,5$ df in proportion to $F(1,5)=6.61$, associated with $p=.05$.

positive deflection from about 175 to $375 \mathrm{msec}$ poststimulus, reflected the contributions of at least three different suppression effects. The earliest effect was due to the relative orientation of the continuous and flashed gratings. This orientation-specific effect was independent of spatial frequency, began at about $100 \mathrm{msec}$, and was most reliable at 125 and $230 \mathrm{msec}$. This effect accounted for most of the suppression of the negative deflection and a portion of the suppression of the subsequent positive deflection. The next effect was due to the relative size of the continuous and flashed bars. The size-specific effect was independent of orientation, began at about $230 \mathrm{msec}$, and was most reliable at about $275 \mathrm{msec}$. It was relatively small and accounted for only a small amount of suppression of the positive deflection. A third effect was due to the interdependence of the effects of the size and orientation of the continuous grating in relationship to the flashed grating. This grating-specific effect, associated with the conjunction of a particular size and orientation in both the flashed and continuous gratings, began at about $250 \mathrm{msec}$ and reached its maximum between 275 and $320 \mathrm{msec}$. It accounted for a small amount of suppression of the negative deflection between 75 and $175 \mathrm{msec}$ and a major portion of the suppression of the positive deflection between 175 and $375 \mathrm{msec}$. The effects of suppression on the behavioral measure of observer sensitivity $\left(\mathrm{d}^{\prime}\right)$ were similar to those primarily reflected by the late positive portion of the VEP-behavioral suppression was evident primarily when the flashed and continuous bars were the same size and orientation.

\section{DISCUSSION}

\section{The Locus and Nature of Continuous Grating Effects}

Since pattern-specific suppression was observed in the interocular as well as the intraocular viewing conditions, it is reasonable to conclude that the locus of the suppression is cortical rather than retinal. The binocular interaction observed in LGN cells of the cat (Noda, Tamaki, \& Iwama, 1972) is not orientation specific, and therefore different in nature from the suppression observed here. The interocular nature of the suppression, along with the evidence that the components of the VEP between 75 and $160 \mathrm{msec}$ are generated in visual cortex (Jeffreys \& Axford, $1972 \mathrm{a}, 1972 \mathrm{~b}$ ) indicates that the size and orientation effects in the present study are mediated by binocular size and orientation channels in visual cortex.

We interpret the waveform of the VEP obtained when the flashed grating was identical to the continuous grating as reflecting the suppression of pattern information processing. This interpretation may be justified on two grounds: First, this interpretation is consonant with the psychophysical data. The detectability of the flashed bars was lowest when they were identical in orientation and size to the continuous bars. Second, under what are termed the suppression conditions in the present experiment, VEP components which have previously been demonstrated to reflect pattern information processing exhibited amplitudes characteristic of VEPs elicited by diffuse flashes, even though the evoking stimulus contained pattern. The amplitude at about 100 and $200 \mathrm{msec}$, for example, has been found to be negative and positive, respectively, in response to flashed patterns and to shift positive and negative, respectively, in response to diffuse flashes (Harter \& White, 1970; Reitveld, Tordior Hagenouw, Lubbers, \& Spoor, 1967; Towle \& Harter, 1977). In the present study, when the flashed and continuous (suppressing) gratings were the same orientation and spatial frequency, the 100 -msec amplitude measure was relatively positive and $\overline{\mathrm{P230}}$ (P200) relatively negative, suggesting that these two pattern components were suppressed. The differences in suppression which we have described are due to the interaction of various pattern stimuli. An even greater release from suppression would have been observed if we had included a condition where the continuous eye viewed diffuse light or darkness (Harter, Conder, \& Towle, in press.) The inclusion of such control conditions would have changed the absolute levels of suppression observed, but not the interpretation of the results. 


\section{The Nature of and Interaction Between Information Channels}

Single-unit measures from monkeys indicate that similar pattern information from the two eyes is processed by the same cortical neurons (Schiller, Finlay, \& Volman, 1976a, 1976b). It may be assumed that this was the case in the present experiment when the same grating was presented continuously to the left eye and flashed to the right eye. Presumably, the binocular neurons were saturated in response to the continuous grating, causing the evoked response to the flashed grating to be partially occluded, or suppressed. On the other hand, when the two gratings differed in both orientation and spatial frequency, as when the 36-min horizontal bars were being viewed continuously and the 9-min vertical bars were flashed, the two gratings were each being processed by neurons with receptive fields with different orientation and spatial frequency properties. Under this stimulating condition, the neurons that respond to the 9-min vertical flashed bars were not activated by the continuous stimulus, and were free to respond.

The fact that we have observed suppression of the response to a transient stimulus by a continuous stimulus gives general support to the contention that sustained channels can inhibit transient channels (Breitmeyer \& Ganz, 1976). However, the patternspecific nature of the suppression we observed did not support this contention, because the 36-min flashed grating was not suppressed to a greater degree than the 9-min grating, which, because of its higher spatial frequency content, would be considered a more salient sustained stimulus.

The nature of the VEP suppression as a function of which features were common to the flashed and continuous gratings suggests that at least three types of neurons contributed to the VEPs, each differing in its specificity and time-course of activation. One type presumably has a receptive field organization that makes it sensitive to grating orientation but not to grating spatial frequency. It contributes to the VEP relatively early in the information processing sequence, from 100 to $250 \mathrm{msec}$ poststimulation. A second type presumably has a receptive field organization that makes it sensitive to grating spatial frequency, but not grating orientation, and contributes to the VEP from 200 to $350 \mathrm{msec}$ following the flashed grating. The greater magnitude of the orientation effects, as compared to size effects, suggests a greater number of orientation detectors than size detectors. A third type of neuron presumably has a receptive field organization such that it is sensitive to spatial frequency and orientation, and contributes to the VEP from 250 to $350 \mathrm{msec}$ following the flashed grating. The response specificity and time-course of the third type of neuron suggests that it could receive converging inputs from the orientation- and size-specific neurons.
Since retinal ganglion and LGN cells exhibit size tuning but not orientation tuning, our conclusion that orientation processing precedes size processing may seem surprising. Campbell and Maffei (1971) have suggested this possibility on the basis of psychophysical evidence. In previous experiments, we had observed that manipulating grating orientation (Harter et al., in press) caused suppression at an earlier latency than when we manipulated pattern size (Harter et al., 1976). This situation may exist because of the relatively poor spatial frequency tuning of most cortical cells when compared with their orientation tuning.

If the nervous system encodes a stimulus parameter by making a comparison of the activity in different neurons or channels, the finding that orientationspecific suppression precedes size-specific suppression in time may be the result of the functional organization of size and orientation channels in cortex. If the cortical organization of orientation columns and spatial frequency rows proposed by Maffei and Fiorentini (1977) for cat visual cortex is applicable to humans, an interesting possibility arises. Since LGN afferents in the cat are known to synapse almost exclusively in layer IV neurons in striate cortex, visual information may initially arrive in many orientation channels (columns) but in only one size channel (spatial-frequency row). Activity may then spread to the cells in other layers of cortex (and other size channels) (Bishop \& Clare, 1953). Theoretically, this type of organization would enable comparisons between orientation channels before size channels.

The conclusion that orientation channels are active earlier in time than size channels may be criticized in that data have been presented indicating "sizespecific" effects at and preceding $150 \mathrm{msec}$ poststimulation (Harter et al., 1976; Smith \& Jeffreys, 1978). This criticism may be unfounded for a number of reasons. The Smith and Jeffreys study differed from the present one in that they used a masking paradigm; they stimulated different portions of the visual field and recorded from different electrode positions; they did not compare the magnitude of the effects of spatial frequency and orientation on the early VEP components; and they used a constant luminance pattern stimulation technique. More relevant, in their and our earlier studies, the independence of spatial frequency and orientation effects was not established; only one feature of the suppressing gratings was changed from different from to identical to the evoking grating. These earlier data, therefore, are comparable to those presented in Figure $4 \mathrm{C}$ in the present study. If this comparison is made, the present data corroborate earlier data showing decreased amplitude of a negative component peaking between 100 and 150 msec poststimulation (Harter et al., 1976; Harter et al., 1977; Smith \& Jeffreys, 1978; Harter 
et al., in press). As noted above, this type of change confounds a pattern-specific effect with the featurespecific effect. It is possible, therefore, that the early size effects in previous studies reflect a patternspecific effect rather than a true size-specific effect.

The decrease in amplitude of the positive component (negative shift) peaking between 200 and $300 \mathrm{msec}$ in the present study has not been reported in previous studies of size- and orientation-specific suppression (Harter et al., 1976; Harter et al., 1977; Smith \& Jeffreys, 1978; Harter et al., in press). The reason for the differences in suppression for the late, but not early, measures in this and the previous series of experiments is most likely due to the nature of the behavioral tasks that were required of the subjects. In contrast to the previous studies, the present one required subjects to make a psychophysical judgment concerning the nature of each flash and to give a "go/no-go" finger-lift reaction-time response within $375 \mathrm{msec}$ after each flash. This type of task causes a negative shift in VEP amplitude from about 150 to $260 \mathrm{msec}$ following an attended or task-relevant stimulus (Harter \& Previc, 1978; Harter \& Salmon, 1972). The changes in VEP amplitude after about $200 \mathrm{msec}$ poststimulation, therefore, may not directly reflect the suppression of activity in sensory information channels, but may reflect the effect of changes in difficulty in performing the reaction time task under the various suppression conditions (Donchin, Ritter, \& McCallum, 1978; Ritter, Simson, \& Vaughn, 1972; Squires, Donchin, Squires, \& Grossberg, 1977). In the latter interpretation, however, the changes in VEP amplitude could still reflect the suppression of activity in sensory information channels, although indirectly, in that such supprssion would account for the changes in task difficulty and congitive processing.

\section{REFERENCES}

Abadi, R. V. Induction masking-a study of some inhibitory interactions during dichoptic viewing. Vision Research, 1976, 16, 269-275.

Bishor, G. H., \& Clare, M. H. Sequence of events in optic cortex response to volleys of impulses in the radiation. Journal of Neurophysiology, 1953, 16, 490-498.

Blakemore, C., \& CAMpbell, F. W. On the existence of neurones in the human visual system selectively sensitive to the orientation and size of retinal images. Joürnal of Physiology, 1969, 203, 237.260 .

Blakemore, C., Nachmias, J., \& Sutton, P. The perceived spatial frequency shift: Evidence for frequency selective neurones in the human brain. Journal of Physiology, 1970, 210, 727-750.

Blakemore, C., \& Sutton, P. Size adaptation: A new aftereffect. Science, 1969, 171, 245-247.

Breitmeyer, B. G., \& GANZ, L. Implications of sustained and transient channels for theories of visual pattern masking, saccadic suppression, and information processing. Psychological Review, 1976. 83, 1-36.
Campbell, F. W., \& Kulikowski, J. J. Orientational selectivity of a human visual system. Journal of Physiology, 1966, 187, 437.445.

Campbell, F. W., \& Maffei, L. Electrophysiological evidence for the existence of orientation and size detectors in the human visual system. Journal of Physiology, 1970, 207, 635-652.

Campbell, F. W., \& Maffe1, L. The tilt after-effect: A fresh look, Vision Research, 1971, 11, 833-840.

Camprell, F. W., \& Robson, J. G. Applications of Fourier analysis to the visibility of gratings. Journal of Physiology, $1968,197,551-566$.

Dixon, W. J. (ED.). Biomedical computer programs. Berkeley: University of California Press, 1975.

Donchin, E., \& Heffley, E. Multivariate analysis of eventrelated potential data: A tutorial review. In D. Otto (Ed.), Multidisciplinary perspectives in event-related brain potential research. Washington, D.C: U.S. Government Printing Office, 1978.

Donchin, E., Ritter, W., \& McCallum, W. C. Cognitive psychophysiology: The endogenous components of the ERP. In E. Callaway, P. Tueting, \& S. H. Koslow (Eds.), Event-related brain potentials in man. New York: Academic Press, 1978.

Georgeson, M. A. Spatial frequency selectivity of a visual tilt illusion. Nature, 1973, 245, 43-45.

Gitinsky, A. S., \& DoherTy, R. S. Interocular transfer of orientational effects. Science, 1969, 164, 454-455.

Gilinsky, A. S., \& Mayo, T. H. Inhibitory effects of orientational adaptation. Journal of the Optical Society of America, 1971, 61, 1710-1714.

Green, D., \& Swets, J. Signal detection theory and psychophysics. New York: Wiley, 1966.

Harter, M. R., Conder, E. S., \& Towle, V. L. Orientationspecific and luminance effects: Interocular suppression of visual evoked potentials. Psychophysiology, in press.

Harter, M. R., \& Previc, F. H. Size-specific information channels and selective attention: Visual evoked potential and behavioral measures. Electroencephalography and Clinical Neurophysiology, 1978, 45, 628-640.

Harter, M. R., Previc, F. H., \& Towle, V. L. Evoked potential indicants of size- and orientation-specific information processing: Feature-specific sensory channels and attention. In D. Lehmann \& E. Callaway (Eds.), Human evoked potentials: Applications and problems. New York: Plenum Press, 1979.

Harter, M. R., \& Salmon, L. E. Intra-modality selective attention and evoked cortical potentials to randomly presented patterns. Electroencephalography and Clinical Neurophysiology, 1972, 32, 605-613.

Harter, M. R., Towle, V. L., \& Musso, M. F. Size specificity and interocular suppression: Monocular evoked potentials and reaction times. Vision Research, 1976, 16, 1111-1117.

Harter, M. R., Towle, V. L., Zakrzewski, M., \& Moyer, S. M. An objective indicant of binocular vision in humans: Size-specific interocular suppression of visual evoked potentials. Electroencephalography and Clinical Neurophysiology, 1977, 43, 825-836.

Harter, M. R., \& White, C. T. Evoked cortical responses to checkerboard patterns: Effect of check-size as a function of visual acuity. Electroencephalography and Clinical Neurophysiology, 1970, 28, 48-54.

Jeffreys, D. A., \& AXForD, J. G. Source locations of patternspecific components of human visual evoked potentials. I. Component of striate cortical origin. Experimental Brain Research, 1972, 16, 1-21. (a)

Jeffreys, D. A., \& Axford, J. G. Source locations of patternspecific components of human visual evoked potentials. II. Component of extrastriate cortical origin. Experimental Brain Research, 1972, 16, 22-40. (b)

Maffei, L., \& Frorfintini, A. Processes of synthesis in visual perception. Nature, 1972, 240, 479-481. 
Maffei, L., \& Fiorentini, A. Spatial frequency rows in the striate cortex. Vision Research, 1977, 17, 257-264.

Mecacci, L., \& Spinelli, D. The effects of spatial frequency adaptation on human evoked potentials. Vision Research, 1976, 16, 477-479.

Musso, M. F., \& Harter, M. R. Visually evoked potentials and selective masking with patterned flashes of different spatial frequencies, Vision Research, 1975, 15, 23!-238.

NodA, H., TAmaki, Y., \& Iwama, K. Binocular units in the lateral geniculate nucleus of chronic cats. Brain Research, 1972, 41, $81-99$.

Pantle, A., \& Sekuler, R. Size-detecting mechanisms in human vision. Science, 1968, 162, 1146-1148.

Parker, D. M. Contrast and size variables and the tilt aftereffect. Quarterly Journal of Experimental Psychology, 1972, 24, 1-7.

Reitveld, W. J., Tordior, W. E. M., Hagenouw, J. R. B., Lubbers, J. A., \& Spoor, A. C. Visual evoked responses to blank and to checkerboard patterned flashes. Acta Physiologica et Pharmachologica Neerlandica, 1967, 14, 259-285.

Ritter, W., Simson, R., \& Vaughan, H. G., Jr. Association cortex potentials and reaction time in auditory discrimination. Electroencephalography \& Clinical Neurophysiology, 1972, 33, 547-555.

Schiller, P. H., Finlay, B. L., \& Volman, S. F. Quantitative studies of single-cell properties in monkey striate cortex. II. Orientation specificity and ocular dominance. Journal of Neurophysiology, 1976, 39, 1320-1333. (a)

Schiller, P. H., Finlay, B., \& Volman, S. F. Quantitative studies of single-cell properties in monkey striate cortex. III. Spatial frequency. Journal of Neurophysiology, 1976, 39, 1334-1351. (b)

Schwent, V. L., Hillyard, S. L., \& Galambos, R. Selective attention and the auditory vertex potential. I. Effects of stimulus delivery rate. Electroencephalography and Clinical Neurophysiology, 1976, 40, 604-614.
Smith, A. T., \& JefFreys, D. A. Size and orientation specificity of transient visual evoked potentials in man. Vision Research, 1978, 18, 651-655.

Squires, N. K., Donchin, E., Squires, K. C., \& Grossberg, S. Bisensory stimulation: Inferring decision-related processes from the P300 component. Journal of Experimental Psychology: Human Perception \& Performance, 1977, 3, 299-315.

Towle, V. L., \& HaRter, M. R. Objective determination of human visual acuity: Pattern evoked potentials. Investigative Ophthalmology, 1977, 16, 1073-1076.

Ware, C., \& Mrtchell, D. E. The spatial selectivity of the tilt aftereffect. Vision Research, 1974, 14, 735-737.

WINER, B. J. Statistical principles in experimental design (2nd ed.). New York: McGraw-Hill, 1971.

WYatT, H. J. Singly and doubly contingent after-effects involving color, orientation and spatial frequency. Vision Research, 1974, 14, $1185-1193$.

\section{NOTES}

1. See "Definition of Terms" section.

2. To compensate for the $50 \%$ reduction in light flux due to the beam splitter in the right half of the haploscope, either a checkerboard or a 9-min grating was placed behind the diffusing screen in the left eye. It was later discovered that the luminance transmittance of these two patterns was not exactly the same. When the grating was positioned behind the diffusing screen, the display was about $1 \mathrm{ml}$ brighter than when the checkerboard was in position. The net effect was to make the continuous grating slightly brighter when it was being viewed by the left eye (interocular viewing condition).

(Received for publication June 1, 1979; revision accepted November $28,1979$. ) 